UDK 78.01(091)

\author{
Reinhard Strohm
}

Fakulteta za glasbo Univerze v Oxfordu

Faculty of Music, Oxford University

\title{
Postmoderni problemi v evropskem glasbenem zgodovinopisju
}

\author{
Povzetek
}

\begin{abstract}
Razprava se ukvarja s vprašanjem, kaj vse se lahko glasbeno zgodovinopisje nauči od postmodernega diskurza, ki se odvija okoli nas. Splošne zgodovinske implikacije koncepta "postmodernizma" kot izboljšave in napredka glede na "modernizem" se kažejo kot protislovje lastnemu sporočilu o nezaupljivosti do progresističnih meta-pripovedi. Opravljena je bila primerjava med negativnim odnosom do srednjeveške preteklosti, kakršnega je najti v okviru renesančnega humanizma ("razcepljena retrospekcija"), in postmodernimi diskurzi, ki naravnavajo isto optiko na zadnjih 200-250 let zahodne kulture. Upoštevanih je nekaj postmodernih pripovedi, ki zadevajo glasbo: antimodernizem, gibanje za baročno in zgodnjo glasbo, recepcija zgodnje opere in razprave o konceptu umetniškega dela, njegovi avtonomiji in avtorstvu. Razprava opozarja na nevarnost žrtvovanja Lyotardove definicije postmodernizma kot "nezaupanja meta-pripovedim" $v$ korist nove meta-pripovedi, ki uvaja razdvojeno retrospekcijo, s katero se ločuje zavrnjena modernistična preteklost od "šele pred kratkim" doseženega preboja ali "morskih sprememb" v kulturoloških raziskavah.
\end{abstract}

Sečišča postmoderne misli in zgodovinopisja evropske glasbe niso zelo obsežna. Postmoderno razpravljanje se ne omejuje samo na glasbo, ampak zaobjema vso kulturo in vse umetnosti. Razen tega se to razpravljanje ne zanima kaj preveč za zgodovino: bolj malo je povezav med postmoderno mislijo in zgodovinsko mislijo. Kljub temu pa ena povezava obstaja, tako da je zanimivo raziskovati, kaj si imata postmoderna in zgodovinopisje evropske glasbe drug drugemu povedati.

\section{Zgodovinska periodizacija "modernega" in "postmodernega"}

Izraza "moderen" in "postmoderen" se po svoji definiciji umeščata v kronološko in historiografsko mrežo odnosov. Imata svoj prostor v arhitekturi historične periodizacije, sta v funkcionalnem odnosu med seboj. Naravo tega odnosa dojemamo v kronološkem 
smislu, gre pa tudi za normativni odnos. Tisto, kar je "postmoderno", naj bi prekosilo, prehitelo ali premagalo "moderno": konotacija vsebuje idejo človeškega napredka. V kolikor termin zaobsega historično periodizacijo, vključuje tudi trditev, da se pred našimi očmi (ali za našimi hrbti) odvija nič manj kot epohalna sprememba. Pravzaprav imamo opraviti s celo množico izrazov ter $z$ razpravljanjem o medsebojno povezanih pojmih, $s$ katerimi ljudje tržijo svoje uspehe. V angleščini je s tem tesno povezan izraz "morska sprememba“, torej velika, a obenem čudovito neboleča transformacija, ki naj bi jo doživela kultura, kritika, znanost ali politika. V podobnih krilaticah, kot na primer "nova kritika", "nova muzikologija", "novi historicizem", "transavantgardizem", ni nikakršnega namiga o vsebini spremembe; gre za "odprte", enostavne in celo skromne izraze, ki poudarjajo napredek. Navajajo na občutek odrešitve, da, skoraj osvoboditve "izpod" nekdanjega kulturnega in političnega okolja, $v$ katerem smo trpeli in ki smo se ga sedaj pod pojmom "modernizem" naučili poimenovati in zavračati.

Sprožitev "postmodernizma“ je močno pripomogla k temu, da se ponovno opredeli in ovrednoti modernizem. Na primer: zgodnja uporaba termina za stile $\mathrm{v}$ ameriški arhitekturi je že v zgodnjih tridesetih letih pripomogla k opredelitvi "modernistične" arhitekture; do podobnega procesa je prišlo v glasbi, v kateri je bila serialnost na splošno bolj znana pod pojmom "modernizma", in to prav v istem kontekstu zavračanja s strani "posmodernih" skladateljev, za katere je značilen bolj sproščen odnos do tonalnosti ali do starejših stilov. V literaturi je posmoderna reakcija Umberta Eca na kulturo srednjega veka $\mathrm{z}$ njegovim romanom Ime rože pomagala nekaterim njegovim bralcem ponovno opredeliti modernistični pristop ne le kot ločitev med dobami ampak med odnosi do preteklosti. V svojem dostavku k Imenu rože (1980) Eco ponuja "metahistoričen" opis modernizma ("avantgarda vedno hoče poravnati račune $s$ preteklostjou) in postmodernizma (ki v smislu manirizma kot obnavljajočega se odnosa do preteklosti slednjo ponovno, pa čeprav ironično, obiskuje). Tako gre pri obeh odnosih za skoraj ciklična dogodka, ki prideta in odideta in ki nista vezana na določene dobe. ${ }^{1}$ Tudi Jean-François Lyotard, ki se zaveda izziva, po katerem naj bi postmodernizem bil v resnici skrajna oblika modernizma (Wolfgang Welsch), predlaga nekakšno intarzijo obeh: "Vsekakor gre pri tem (sc. postmodernem) za del modernega ... neko delo lahko postane moderno samo, če je poprej postmoderno. Če tako razumemo postmodernizem, potem nimamo opraviti s koncem modernizma ampak z modernizmom v porajajočem se stanju, in to stanje je konstantno “. ${ }^{2}$ Soočeni smo s skoraj ventrilokventnim odnosom med obema izrazoma: ko rečemo "postmoderno", etiketiramo in vrednotimo "moderno", in ko se odločimo reči "moderno", se dandanes že zavedamo, da s tem impliciramo velik oklepaj okoli vsega, kar je "postmoderno".

U. Eco, 'Postilla', v Il nome della rosa, Milano, 14. izd., 1980, str. 529-530; U. Eco, Documenti su il nuovo medioevo, Milano, 1973; za oboje gl. Wolfgang Welsch, Unsere postmoderne Moderne, Weinheim, 1987, str. 57-59.

J.-F. Lyotard, 'Answering the question: What is Postmodernism?' (1982), prev. R. Durand, v J.-F. Lyotard, The Postmodern Condition: A Report on Knowledge, prev. G. Bennington and B. Massumi, uvod Fredric Jameson, Minneapolis: U. of Minnesota Press, 1984, str. 79. 


\section{2. "Srednji vek" in deljena retrospekcija}

To, kar naj bi označili kot historiografsko funkcijo konceptualnega para "modernopostmoderno ", funkcijo, s katero omenjena pojma opredeljujeta zgodovino, ima seveda svoje predhodnike v sami zgodovini. Zato ne preseneča, da renesančni humanizem - ta izrazita evropska inovacija - in začetek "moderne dobe" nam z iznajdbo termina "srednjega veka" ponujata neposreden vzorec postmodernega izrazoslovja. Gre za historiografski termin, ki podobno kot "postmoderno" ne opredeljuje samo sebe ampak refleksijsko tudi druga obdobja.

Pojem so ustvarili renesančni humanisti, ki so ponosnoverjeli, da so prehiteli in presegli neko dobo. Čeprav niso iznašli imena za svoje lastno, post-srednjeveško razdobje (v tem je določena razlika v "postmodernem" razpravljanju), so si izmislili označbo "srednji vek" za predhodno obdobje. Tak termin, ki definira določen časovni razpon, je kronološko dovolj učinkovit, da more vse ostalo identificirati ali kot "pre(d)-» ali kot "post-». Z enim novim izrazom so humanisti ustvarili tri razdobja. ${ }^{3}$ Novo obdobje, ki naj bi ga bili dosegli, se je pozneje imenovalo "moderna doba". ${ }^{4}$

Čeprav danes vemo, da je pojem "srednjega veka" samovoljna iznajdba, kaže, da se ga navkljub mnogim resnim očitkom glede njegovih konotacij ne moremo znebiti. Morda je iskati vzrok prav v zgodovinskih predsodkih in samorazkazovalnosti, ki so jih stlačili v ta izraz: zdi se, da kritični presoji laže uidemo kot pa zgodovinskim normam in predsodkom. Tudi najbolj pretanjena in znanstveno uravnovešena historiografska označba za pred-kolumbovsko obdobje ne more nadomestiti recepcijskega uspeha "temnega srednjega veka", ker gre pri tem za ideološke temelje naše zgodovinske retrospektive, ki nam je pomagala pretolči moderni čas.

Moderna doba se je začela okoli 1500 , in to z zavestno ločitvijo humanistov od neposredne preteklosti, z zavrnitvijo te preteklosti in z nostalgičnim prevrednotenjem ali obnavljanjem neke zgodnejše preteklosti - antike. Ko so se ozirali nazaj v antične čase, so čutili, da je to bila kulturno bolj dostojanstvena doba, ki se je ob koncu rimskega imperija zaključila s "padcem v nemilost", ki sta mu sledila propad in tema. Za ta nasprotujoči si odnos do dveh ločenih preteklosti predlagam termin "razcepljene retrospektive", pri čemer nagibljem $k$ primerjavi $z$ antropološkim fenomenom sovraštva do očeta ter ljubezni do starega očeta. ${ }^{5}$

Če bi tako retrospekcijo sprejeli v našem času, bi morali nekaj zadnjih stoletij poimenovati s "srednjim vekom" in obenem razviti nostalgijo za neko zgodnejšo preteklost, morda za obdobje sedanjega srednjega in zgodnjega novega veka skupaj, za čas t. i.

Jürgen Voss, Das Mittelalter im historischen Denken Frankreich. Untersuchungen zur Geschichte des Mittelalter-Begriffes, München, 1972, str. 40-42; Nathan Edelmann, 'The Early Uses of "Medium Aevum, Moyen Age, Middle Ages'،, Romanic Review29, 1938, str. 3-25; R. Strohm, 'The End of the Middle Ages, referat na Medieval and Renaissance Studies Symposium Novacella 1998, Annegrit Laubenthal, ur. (Hildesheim, Olms, v tisku).

Sprejetje ideje, da se živi v "moderni dobi ‘ je trajalo dalj časa: gl. R. Koselleck, "Neuzeitu. 'Zur Semantik moderner Bewegungsbegriffe', v R. Koselleck, Vergangene Zukunft. Zursemantik geschichtlicher Zeiten, Frankfurt/M.,1992, str. 300-348.

Glede nadaljnjih misli gl. R. Strohm, 'The Humanist Idea of a Common Revival of the Arts, and its Implications for Music History', v M. Jablonski in J. Steszewski, ur. Interdisciplinary Studies in Musicology. Report from the Third Interdisciplinary Conference Poznan 1996, Poznan, 1997, str. 7-25. 
ancien régime. Dejstvo je namreč, da nekateri zgodovinarji ne ločujejo več srednjega veka od zgodnjega novega, ki mu sledi, tako da na primer Jacques Le Goff govori o "dolgem srednjem veku“. ${ }^{6}$ Mnogi ljudje so danes začeli ponovno ceniti predindustrijske čase in njihovo kulturo ter se po njih nostalgično ozirajo, kot so se renesančni humanisti ozirali po antiki; tudi bolj kritični so do zadnjih 200-250 let - kar bi lahko označili kot obdobje modernizma, ${ }^{7}$ t. j. osovraženo obdobje naših konfliktov z naravo, $z$ neindustrializiranim svetom in z metafizičnim. Mnogi sodobniki govorijo o tem obdobju s stališča antiracionalizma, antimodernizma in antiuniverzalizma. Evropsko razsvetljensko buržoazno revolucijo interpretirajo kot "padec v nemilost ${ }^{8}$. To pa so ravno tendence, za katere se od zgodnjega dvajsetega stoletja dalje zavzema t. i. "medievalizem" in jih dandanes razglaša postmoderna filozofija zgodovine, pri kateri je razdobje med ca. 1780 in ca. 1980 prevzelo negativno vlogo temnega srednjega veka.?

Vendar: razlikovanje zgodovinskih obdobij na podlagi normativnosti njihovih glavnih značilnosti in vodil implicira imenitno zaokroženo teleologijo napredka in propada oziroma urejevanje časa s prostorsko mrežo, kar pa so za postmoderniste nesprejemljivi pogledi, proti katerim se borijo, saj njihova drža goji ironijo in zaobjema raznovrstno. Vodilni pisci pravijo, da postmodernizem ne poizkuša ustvariti novih periodizacij in promovirati neke "veličastne pripovedi" o napredku, emancipaciji in univerzalnih resnicah. ${ }^{10}$ In zopet: ravno ideja, da smo prišli do konca modernističnega obdobja, v katerem so te pripovedi cvetele, implicira tako zgodovinopisje, ki ga mora postmodernizem - s svojo držo ironičnosti in raznovrstnosti-zavrniti. $Z$ drugimi besedami, antimodernizem postmoderne historiografije je protisloven samemu sebi.

\section{Antimodernizem v dvajsetem stoletju}

Skušajmo sestaviti nekoliko bolj konkretno podobo antimodernizma, njegovih značilnosti, zgodovine in načinov učinkovanja. Postmoderni teoretiki opisujejo svoj antimodernizem tudi z izrazom antiracionalizem in antiuniverzalizem. Antiuniverzalizem je pomenljiv, ker nasprotuje historiografski in ne le filozofski presoji, da se kulturni, znanstveni in družbeni razvoji nenehno širijo, kar naj bi bila velika "meta-pripoved" univerzalnega napredka. Lyotard označuje postmodernizem kot "dvom v meta-pripoved", $s$ čimer implicira pomembne zgodovinske in filozofske ideje o človeštvu in družbi, ki so bile izrečene v zadnjih 200-250 letih. Na misel pridejo imena, kot so Kant, Hegel, Marx, Nietzshe, Adorno - sled pretežno idealistične in pretežno nemške filozofije.

Nikakor pa nista antiuniverzalizem in antiracionalizem postmoderni iznajdbi. Nasprotovanje pravkar omenjenemu tipu filozofije je del iste evropske tradicije; kritične,

6 Jacques Le Goff, L'imaginaire médiéval. Essais, Paris, 1985.

Prepričljivo utemeljitev, da ima 'modernizem', ki se ga često postavlja v čas med ca. 1890 in ca. 1960, svoje korenine sredi osemnajstega stoletja, je najti v Hans Robert Jauss, 'Der literarische Prozess des Modernismus von Rousseau bis Adorno', v R. Herzog in R. Koselleck, ur. Epochenschwelle und Epochenbewusstsein, München, 1987, str. 243-268.

8 Na splošno o tej usmeritvi gl. R. Strohm, 'Collapsing the dialectic. The enlightenment tradition in music and its critics', v Tim Carter, ur. IMS $16^{\text {th }}$ International Congress Report London/Oxford/Cambridge 1997, Round Table "Historiography* (predsedujoči Manuel Carlos de Brito) (Oxford 2000; v tisku).

9 To analogijo je (z drugačnim zaključki) obravnaval Peter Von Moos, 'Gefahren des Mittelalterbegriffs. Diagnostische und präventive Aspekte', v Joachim Heinzle, ur. Modernes Mittelalter. Neue Bilder einerpopulären Epoche, Frankfurt/M.,1994. str. 33-63.

10 J.-F. Lyotard, 'Answering the question: What is Postmodernism?' (op. 2), zlasti odstavka 9 in 10. 
a tudi nostalgične podobe zahodne modernosti že vsaj od Rousseauja in razsvetljenstva osemnajstega stoletja dalje zaznamuje naše intelektualne tradicije. Situacijo je diagnosticiral Max Weber, ki je videl bistvo modernosti v konceptu "racionalizacije" in definicijo ideologije v uzakonitvi moči. Ta kritičen pogled modernosti kot celote-ki racionalizira, ki je ideološki - je torej značilen za Adorna, Habermasa in za postmoderne pisce, ki so širše zastavili vprašanje uzakonitve legitimnosti. Nasprotje med razumom in ideologijo ali med civilizacijo in mitom obdeluje knjiga Dialektik der Aufklärung Theodorja W. Adorna in Maxa Horkheimerja, delo, ki odseva obup štiridesetih let in ki so ga desno usmerjeni kritiki kaj kmalu razlagali kot priznanje poraza s strani modernistov samih. ${ }^{11}$ Gre za izkušnjo jalovosti napredka in polomijo prespektivne, univerzalno pomembne "meta-pripovedi", ki je spremljala celotno "modernistično ero", pa naj jo že kakorkoli definiramo, in ki je prešla $v$ svojo radikalno komponento $-\mathrm{v}$ postmodernizem. Dva izmed vodilnih razpravljalcev sedemdesetih let, Jürgen Habermas in Jean-François Lyotard, sta iskala nove načine ločevanja resničnih trditev od napačnih ter legitimiranja družbene ureditve. Habermas se je osredotočil na konsenz in avtoriteto, ${ }^{12}$ Lyotard pa na jezik in jezikovne igre; slednji je predlagal, da se zgodovina uporabi kot kontraprimer modernistični meta-pripovedi o rasti znanja in kulture. Zato predlagam, da se ponovno vrnemo na zgodovinsko točko, na kateri je bila nekoč utemeljena ta meta-pripoved, in da vidimo, ali nas more voditi do alternativnih interpretacij. $Z$ drugimi besedami: ponovno moramo obiskati preteklost, da bi odkrili alternative, ki so bile zavrnjene pri oblikovanju modernistične pripovedi. Modernizem in njegovo legendo napredka bi morali premagati zgodovinski dokazi izven njegove jurisdikcije. Torej: zgodovinski trenutek, ki je utemeljil legendo napredka; je bil evropsko razsvetljenstvo; zgodovina izven njegove jurisdikcije pa je ancien régime ali, z Jacques Le Goffovim izrazom, "dolgi srednji vek".

\section{Alternativno igrišče: baročna in zgodnja glasba}

Mnogi antimodernisti bi zgodovino, ki je zunaj moderne jurisdikcije, označili s pojmom "barok", ključno besedo za kulturo, v kateri še ni bilo modernega racionalizma oziroma se je začenjal komaj pojavljati. Michel Foucault je bil eden izmed tistih zgodovinarjev, ki so smatrali, da določen konceptualni okvir združuje sedemnajsto in osemnajsto stoletje in ju ločuje od modernosti, kot se to na primer kaže v odnosih med resničnostjo in domišljijo, med razumom in norostjo. ${ }^{13}$ Postmoderne oživitve baročne estetike $\mathrm{v}$ umetnosti ugovarjajo modernemu racionalizmu in suženjstvu napredka; oživljanje baročne pastorale, ki naj bi bila osvobojena nasilja in institucij, pa vsebuje kritične poteze. Pri tem gre tudi za zemljepisno diferenciacijo: mediteranska in južnoameriška umetnost in literatura že dolgo časa obnavljata baročno estetiko in se s tem jasno odmikata od germanske in severnjaške prakse in ideologije. ${ }^{14}$

\footnotetext{
T. W. Adorno in M. Horkheimer, Dialectic of Enlightenment (1947), prev. J. Cumming, London, 1979.

J. Habermas, Legitimationsprobleme im Spätkapitalismus, Frankfurt/M., 1973.

M. Foucault, Les mots et les choses, Paris, 1966; Historie de la folie à l'áge classique, Paris, 1967.

Arabella Pauly, Neobarocco, New York - Berlin, 1993; Gertraud Strohm-Katzer, 'José de Sigüenza in Carlos Fuentes. Die Erfindung des Escorial und seine poetische Transformation', v M. Bosse in A. Stoll, ur. Theatrum Mundi. Figuren der Barockästhetik in Spanien und Hispano-Amerika, Bielefeld, 1997, str, 43-72; Volker Roloff, 'Labyrinth der Lektüre. Figuren der Intermedialität bei Borges, Cortázar und Carpentier', ibid., str. 253-274.
} 
Baročna umetnost, glasba in gledališče so postala nebesa za disidente modernosti, igrišče za zlorabljene otroke preveč razumsko usmerjenih in tehniziranih civilizacij. Te pripombe vodijo seveda $\mathrm{k}$ mnogim možnim nasprotjem. Vzemimo na primer Walterja Benjamina ponovno ovrednotenje baročne tragedije in njene značilne, postmoderne tragičnosti; $;^{15}$ ali, Rolanda Barthesa očaranost nad ceremonialnostjo baročne drame, ali Benjaminovo ali Foucaultovo zavračanje aristotelovske mimeze v prid simboličnosti in alegoriji. Seveda pa imajo vsa ta prevrednotenja tudi svojo dialektično modernistično predzgodovino: tako se je na primer zanimanje za simbole in alegorijo ali za predklasično tragedijo začelo že z romantiki.

Paradigma "zgodnje glasbe" ima prav tu svoje mesto, pa čeprav vsebuje v sebi tudi lastno nasprotje. Vsi jo poznamo kot glasbeno igrišče odpadništva od komercializirane in tehnizirane popularne glasbe. Zavračanje take drže kot bega je bila neizogibna reakcija vodilnih modernistov kot Theodorja W. Adorna, ki je očital gibanju za "zgodnjo glasbo" estetsko nazadovanje in politični agnosticizem; zelo podobno se je izražal tudi o "jazzu ". ${ }^{16}$ Adorno se takrat pač ni zavedal postmodernega diskurza; ko je ta diskurz dosegel "zgodnjo glasbo", je bila slednja "razkrinkana" kot modernistična tendencioznost, kot deviantna obsedenost s togo zvočnostjo in regresivno tehnizacijo. ${ }^{17}$ Zanimivo, da imamo opraviti z vzporedjem postopkov v "Zgodnji glasbi“ in v modernističnem avantgardnem komponiranju, ki se kažejo v vse večji pozornosti kakovosti zvoka in zvočnosti, pri čemer ne gre le za zasedbo in uporabo instrumentov, ampak za tehnično oblikovanje določenih zvočnih spektrov. Zdi se komaj presenetljivo, da je možno povezovati estetiko "zgodnje glasbe" z glavnim tokom modernizma; vendar pa ta primer priča, da jurisdikcija modernizma sega veliko dlje, kot se ponavadi misli.

Toda, mar ni res, da se posebna ljubezen do "zgodnje glasbe u ukvarja zlasti z vprašanji "obnove", "izvedbe in "neavtorske umetnosti", in da se ta tri vprašanja križajo s postmodernimi interesi? Preporod stare glasbe iz časov pred razsvetljenim obdobjem, njeno ponovno ovrednotenje ali revizitacija (da uporabimo Ecov izraz), je lahko nostalgična ali tudi ironična, vendar prav gotovo teži po kulturi izven modernih tokov napredka. Poleg sorodnosti med produkcijo "zgodnje glasbe in avntgardnim komponiranjem je tudi res, da prizadevanja $\mathrm{v}$ zvezi z "zgodnjo glasbo" merijo na bolj vseobsežno revivifikacijo, na človeške izkušnje znotraj revitaliziranega okolja. Takšni cilji pa še kako spominjajo na napore humanistov, da bi ne le odkrili starodavne tekste, ampak da bi z njihovimi nauki preoblikovali sodobno življenje. V istem smislu, kot sem humanistično zgodovinopisje (z razcepljeno retrospekcijo) primerjal s postmoderno historično teorijo, lahko sedaj trdim, da obstajajo paralele med nostalgijo za "zgodnjo glasbo in nostalgijo humanizma. Vprašanje izvedbe je zelo pomembno za glasbenike našega časa, zlasti kot nasprotje s "konceptom opusa "in avtorstva. Potencialno postmoderne zvrsti glasbe, pa naj gre za "popularno", "zgodnjo" ali morda "svetovno" glasbo,

15 W. Benjamin, Der Ursprung des deutschen Trauerspiels(1928); prev. kot Origin of German Tragic Drama, London, 1977.

16 Glede Adornovega eseja 'Bach gegen seine Liebhaber verteidigt' (v T. W. Adorno, Prismen. Kulturkritik und Gesellschaft, Frankfurt/M., 1955), gl. Laurence Dreyfus, 'Early Music defended against its devotees: a Theory of historical performance in the twentieth century', Musical Qurterly, 69 (1983), str. 297-322. Glede Adorna o jazzu in popularni glasbi gl. Max Paddison, Adorno, Modernism and Mass Culture. Essays on Critical Theory and Culture, London, 1996, str. 81-105.

17 Richard Taruskin, 'The Pastness of the Present and the Presence of the Past', v Nicholas Kenyon, ur., Authenticity and Early Music. A Symposium, Oxford, 1988, str. 137-207. 
so izrazito izvedbeno usmerjene $\mathrm{v}$ nasprotju s klasično-romantičnim repertoarjem, ki ga hierarhično obvladujeta avtor in tekst. Velika inovacija dvajsetega stoletja, ki zadeva mehansko reprodukcijo glasbe ter materializacijo izvedbenih vidikov glasbenih produktov, je vsekakor prispevala k vzponu izvedbenih teorij in filozofije izvajanja oziroma nastopanja v našem času. Kaže, da ima slednje kompenzacijsko in zdravilno funkcijo: ko izkušamo posnetek oglušujoče žive izvedbe in njeno komercializacijo s strani industrije zabave, odkrivamo njen pomen z vsemi spremljajočimi značilnostmi spontanosti in interakcije. Vendar: čimbolj poveličujemo izvedbeno spontanost, tembolj jo zabrisujemo z raznimi oblikami "mehanske reprodukcije“, ki se kaže kot tipično kontradiktorna, postmoderna okoliščina našega življenja.

\section{Primer opere serie}

Tako so si prenova "zgodnje glasbe in različne antimodernistične tendence blizu tudi $\mathrm{v}$ postmodernističnih diskurzih, in to navkljub dokazom o nasprotnem, ki jih je zbral Taruskin. Vzrok za to dvojno povezavo je iskati v dejstvu, da so moderni in postmoderni diskurzi vsaj v glasbi itak tesno povezani. Primer repertoarja italijanske opere serie in njene historiografije kaže, kako malo se je od dvajsetih let dalje spremenila recepcija predklasične glasbe.

Kot je bilo že omenjeno, so bili že zgodnji pisci dvajsetega stoletja zaskrbljeni glede uspešnosti "meta-pripovedi " o univerzalnosti sprememb. Zdelo se je, da gre za darilo iz nebes, ko se je odkril alternativni prostor na področju opere, še zlasti italijanske opere, katere razvoj naj bi nasprotoval ali celo rušil napredne in racionalne tendence modernosti. Ta zgodovinski pogled na opero je imel še dodatno prednost $v$ tem, da je bil razvpito zmožen razložiti samoprenovo žanra, ko je že bil proglašen za pokojnega. Seveda: vstajenja opere so se že zgodila pod pogojem, da je njene konservativne in antiracionalne podtalne tokove kaznovala vsiljena utemeljitev novih racionalizacij, to je t. i. opernih reform, na katerih, kot se zdi, sloni zgodovina tega žanra.

Kar ločuje moderno in postmoderno operno zgodovinopisje, ni diagnoza teh podtalnih tokov, ampak njihovo vrednotenje. Modernizem zavrača opero in ji verjame, samo v kolikor se reformira; postmodernizem pa tira opero $v$ iracionalni kot in jo poveličuje zavoljo njene nezmožnosti, da bi se reformirala. Navedeni nasprotujoči se predsodki so še posebej očitni $\mathrm{v}$ recepciji italijanske opere serie $\mathrm{v}$ devetnajstem in dvajsetem stoletju, in sicer zato, ker je bil ta žanr sam preizkusni kamen začetnega modernizma srede osemnajstega stoletja, ko so kritiki zaznali odpiranje kulturne vrzeli med racionalnostjo in naravo. Takšen odnos do opere serie osemnajstega stoletja in njenih naslednikov je simptomatičen za krizo modernosti. Od devetnajstega stoletja dalje zgodovinarji ločijo naslednji operni tradiciji: dvorno, mednarodno in mediteransko ter srednjeevropsko, meščansko in nacionalno. Že v osemnajstem stoletju je bila opera seria razdeljena: Hasse in Metastasio sta predstavnika prvih teženj, Gluck in Mozart pa drugih. Ob tem je wagnerjanska pripoved Oper und Drama (1851) o folklornih koreninah opernih form, zlasti arije, in o zlorabi in propoadu te dediščine poglobila dialektiko med južnjaško/čutno operno avreolo in severnjaško/ protestantsko racionalnostjo in učinkovitostjo. Romantiki so radi gojili idejo o pobotanju teh tradicij v klasicizmu (ali 'za wagnerjance' v glasbeni drami). 
Gluckov trden položaj med romantiki sloni na njegovem domnevnem odkritju sublimnega in tragičnega v operi, tako da se njegova reforma kaže skoraj kot nekakšna antiracionalistična iniciativa. Še Carl Dahlhaus je postavljal klasicizem proti razsvetljenstvu v glasbi osemnajstega stoletja, in torej Glucka proti Hasseju, etos proti patosu, pa čeprav v okviru določene razvojne sinteze..$^{18}$ Vprašanje realizma se postavlja pri interpretaciji Mozarta: zopet je romantični diskurz tisti, ki postavlja domnevo o estetski enodimenzionalnosti opere serie na eni in polnokrvni človeški naravnanosti Mozarta in njegovih privržencev na drugi strani.

$\mathrm{Na}$ nekatere druge vidike opere serie so postali pozorni v zgodnjem modernizmu dvajsetega stoletja. Vključevali so tudi domnevno mehansko tipologijo, pravila igre, ki se jih še niso dotaknile individualne dramske psihologije. Zagovarjala se je torej drugačnost postmoderne tradicije, pa čeprav se je ohranjala zgodovinska potreba po njenem zlitju v klasično sintezo. To je bistvo operne kritike Hermanna Aberta in Rudolfa Gerberja ter göttingenskih obnovitev Händlove opere serie v dvajsetih letih. ${ }^{19}$ Racionalizirajo se delitve glasbene kulture, pri čemer se uporabljajo dialektični ali antitetični strukturalni modeli. Abert in Gerbert večkrat govorita o stereotipnosti da cappo arije, a obenem poudarjata, kako so se največji skladatelji opere serie (Händel, Hasse, Jommeli, Mozart) prizadevali preseči ta preprosti obrazec. Podobni orisi veljajo tudi za vprašanja stilnih izvedb in dramaturgije. Tradicionalna opera seria, in z njo večji del baročne opere, je sprejeta do te mere, da je lahko presegla svoje najbolj svojske značilnosti.

Če nadaljujemo s tem avtokontradiktornim, strukturalističnim orisom zgodnje opere, kaže omeniti nekaj bolj raznovrstnih in eklektičnih interpretacij, ki so se med tem pojavile. V šestdesetih letih, ko je kriza konceptov dela in avtorstva dosegla glasbeno zgodovinopisje, so začenjali ponovno odkrivati zgodnjo opero, ki je bila nedolžno stran od teh konceptov, $\mathrm{v}$ stanju umetnosti pred njenim padcem $\mathrm{v}$ nemilost. Ta tolmačenja baročne opere so vplivala na raziskovalne usmeritve. Na primer: namesto biografij skladateljev in analize pomembnih del najdemo obsežne študije libretov ter rezultate raziskovanja posameznih pevcev, gledaliških postopkov in poklicev, in kulturnih konotacij. Na področjih izvedbene prakse in preporoda so se zavzemali za domnevno predklasično estetiko statičnega enobarvnega ali epskega gledališča. Kljub temu so bile vse te težnje na področju raziskovanja in prenovitvene prakse še vedno zasidrane v modernistični tradiciji. Zanimivo, da smo priča določene ambivalentnosti glede konceptov avtorstva in dela: taka znanstvenika, kot sta Dahlhaus in za njim Lorenzo Bianconi, poudarjata zlasti izvenopusne vidike opere pred devetnajstim stoletjem, relativno pomožni status zapisane partiture ter intertekstualnost opernih verzij. Na drugi strani bi lahko dejali, da te značilnosti veljajo za opero nasploh, vsaj za njeno "mediteransko" tradicijo; tega vprašanja se je pred kratkim lotil znanstvenik Harold S. Powers, ki je okaral glasbene zgodovinarje, da so raziskovanja opere "germanizirali"

18 C. Dahlhaus, 'Ethos und Pathos in Glucks "Iphigenie auf Taurisa', Die Musikforschung, 27, 1974, str. 289-300.

H. Abert, Grundprobleme der Operngeschichte, Leipzig, 1926; R. Gerber, Der Operntypus Johann Adolf Hasses und seine textlichen Grundlagen, Leipzig, 1925, glede zgodnje Händlove 'renesanse' gl. U. Etscheit, Händels "Rodelindan: Libretto, Komposition, Rezeption, Kassel (itd.), 1998, str. 239-306. 
$\mathrm{s}$ progresističnimi in analitičnimi meta-pripovedmi. ${ }^{20}$ Vendar je to postmoderno spoštovanje do drugačnosti opere, ki je v nenavadnem nasprotju $z$ izvedbeno prakso ironičnih in eklektičnih uprizoritev, $\mathrm{v}$ svojem bistvu še vedno prepričano o veliki zgodovinski napetosti med predklasično, predreformsko in klasično, reformirano opero, med njenim južnim in severnim tipom. Ti in taki samozvani postmoderni pristopi baročni operi predstavljajo nadaljevanje modernističnih meta-pripovedi.

\section{Koncept avtorstva in dela}

Koncept avtorstva in dela sta najbolj kritično obravnavani "ideologiji، današnjega zgodovinopisja. Mnenja o zgodovini koncepta dela, ki segajo nazaj v nemško muzikologijo Walterja Wiore, Hansa-Heinricha Eggebrechta in Carla Dahlhausa, so se že večkrat ponavljala; močno pa jih je razširila Lydia Goehr s svojo trditvijo, da se je koncept glasbenega dela kot regulativna ideja pojavil šele okoli leta 1800 in da je predstavljal prevladujočo in celo "imperialistično ideologijo romantičnih ter zgodnjih modernih glasbenikov. Kot zdravilo proti taki ozkosti je značilen njen alternativni predlog "zgodnje glasbe " $z$ njenim neavtorskim in predopusnim statusom. ${ }^{21}$ Vendar pa so bile polemike proti središčnosti koncepta glasbenega dela in njegovega avtorstva v klasičnoromantičnem repertoarju in zgodovinopisju močno razgibane že v glasbeni avantgardi petdesetih in šestdesetih let. Šlo pa je za grmenje iz preteklosti, sajje literarna avantgarda, vsaj kar zadeva njeno področje, v tem času že popolnoma izpodkopala ugled avtonomnosti umetniškega dela. ${ }^{22}$ Literarne teorije o pomenu recepcije in načina branja so potlej pridobile na vplivu. Razgrajevalci so izpodbijali tudi estetske principe, ki so sloneli na enovitosti in internacionalnosti glasbenih misli: možna je postala destrukcija klasičnih kompozicij, s tem da se je odkrivalo, v kolikšni meri sta njihovo sporočilo in smisel lastna sprejemnikovem. Možno je bilo razpravljati o disfunkcionalnosti glasbe, in to v času, ko je idealistična tradicija poslušanja smatrala, da deluje na pomensko višji ravni, tako na primer na ravni meta-pripovedi, ki povezuje vse klasično-romantične simfonije. Takšne izzive je sprožila modernistična generacija skladateljev, kot so bili Cage, Stockhausen, Berio, Kagel itd., izzive, o katerih so kritično že razglabljali Adorno in drugi modernisti. ${ }^{23}$

H. S. Powers, 'La solita forma" and "The uses of convention"', v Nuove prospettive della ricerca verdiana. Atti del convegno internazionale in occasione della prima del 'Rigoletto' in edizione critica, 1983, Dunaj-Milano, 1987, str. 75-109 na str. 76.

21 L. Goehr, The Imaginary Museum of Musical Works. An Essay in the Philosophy of Music, Oxford, 1992. Glede koncepta dela v preteklosti in sedanjosti gl. Michael Talbot, ur. The Musical Work: Reality or Invention?, Liverpool University Press, 2000; v tisku; v istem zvezku je moj odgovor Goehrovi: R. S., 'Looking back at ourselves: the problem with the musical workconcept'.

22. Carl Dahlhaus in drugi so zaznali njegov upad v šestdesetih letih; gl. C. Dahlhaus, 'Plädoyer für eine romantische Kategorie. Der Begriff des Kunstwerks in der neuesten Musik', Neue Zeitschrift für Musik, 130/1, 1969, ponatis v C. Dahlhaus, Schönberg und andere, Mainz, 1978, str. 270-279; C. Dahlhaus, 'Über den Zerfall des musikalischen Werkbegriffs', Beiträge 1970/71 der Österreichischen Gesellschaft für Musik, Kassel (itd.), 1971, ponatis, ibid., str. 279-290; Roman Ingarden, Untersuchungen zur Ontologie der Kunst, Tübingen, 1962, prev. kot Ontology of the Work of Art, Ohio University press, 1989, uvod (napisan verjetno leta 1957).

23 Pregled avantgardnih izpodbijanj koncepta glasbenega dela je najti $\mathrm{L}$ L. Goehr, The Imaginary Museum (op. 21 zgoraj), str. 257-284. 
Kaj jim lahko postmoderna teorija pridoda, je kljub temu jasno. Mislim, da so glasbeni zgodovinarji vključno z generacijo Dahlhausa in Meyerja dobrodošlo sprejeli vprašljivost tradicije avtorstva zato, ker je bila še vedno osredotočena na zahodni glasbeni kánon, na repertoar "sui generis" (Walter Wiora), ki je tudi v svojem razgrajenem stanju kazal znamenja drugačnosti vis-à-vis ostalemu svetu. Adornova jedka obravnava gibanja za "zgodnjo glasbo" in za jazz je že točno opredelila postmoderno grožnjo: izšla je iz nejasne, neavtorske umetnosti, predstavitvene umetnosti v najbolj skromnem smislu besede, iz "enega baroka", ki bi se celo mogel zvariti v Moggovem synthesizerju Walterja ali Wendy Carlos, Concierto Barocco ali v nepozabnih "delih"P. D. Q. Bacha, kakor jih je "revaloriziral" Peter Schickele. Naj je šlo za zgodnje različice v smislu tradicije sui generis ali za kasnejše, kot sta Tranquillitude in Organum (zvarki psevdosrednjeveške glasbe na CD), je bistvo postmoderne alternative predstavljala komercializirana, ironična, spretna "izvedbena" glasba, ki je obiskovala in plagirala preteklost. Križišče te sfere "delanja " glasbe z glasbenim zgodovinopisjem bi lahko poimenovali "katastrofalno": ko so moji študenti glasbene zgodovinẹ temu in takemu enkrat slušno izpostavljeni, sem prepričan, da repertoarji srednjega veka, renesanse in baroka niso nikoli več isti.

To je morda prav tisti učinek, ki so ga modernisti predvidevali: medtem ko so dialektično izpodbijali meta-pripovedi konceptov glasbenega dela, avtorstva, značaja teksta in intencionalnosti, je ta usodna zadeva enostavno izhajala s stališča dvoma.

\section{7. "Razvodje" in "morska sprememba" kot meta-pripovedi}

Tako je moje zadnje vprašanje: ali smo sedaj priča novi dobi zahodne glasbene zgodovine in ali vidimo obrise pretekle dobe tako dobro, kakor so renesančni humanisti mislili, da vidijo obrise srednjega veka, oziroma, kakšno je resnično zgodovinsko stanje našega časa in kakšna je njegova zgodovinska retrospekcija?

V svojem referatu, ki ga je pred kratkim imel na posvetovanju o konceptu glasbenega dela ${ }^{24}$ je Michael Talbot povzel historiografsko tradicijo zadnjih petdesetih let, $v$ katerih se, kot kaže, kopičijo najbolj relevantne spremembe v glasbenem življenju Zahoda $\mathrm{v}$ nekaj desetletjih okoli leta 1800 . To obdobje je videti kot nekakšno "razvodje" v razvoju glasbe; druge pomembne zgodovinske spremembe v kulturi Zahoda, ki vplivajo na glasbo, kaže, da pokrivajo s tem mnenjem. Najbolj prepričljivo podporo tej hipotezi je najti v knjigi, v kateri Lydia Goehr piše o konceptu glasbenega dela: "... upoštevaje določene spremembe v poznem osemnajstem stoletju, so posamezniki ... prvič mogli doumeti in obravnavati celotno aktivnost $\mathrm{v}$ zvezi $\mathrm{z}$ ustvarjanjem glasbe predvsem $\mathrm{v}$ smislu skladanja in izvajanja del. Koncept dela je na tej točki našel svojo regulativno vlogo. ${ }^{25}$ Michael Talbot pa prav okoli leta 1800 zaznava "prvi pojav oblikovanja univerzalnega glasbenega 'kánona' ". ${ }^{26}$ Kredibilnost trditev, kakršne so "prvič“, "na tej točki" ali "prvi pojav", bi po mojem morala sloneti na nazornem dokazu, da se vse to

\footnotetext{
M. Talbot, 'The Work-Concept and Composer-Centredness', v M. Talbot, ur., The Musical Work-Concept (op. 21 zgoraj). L. Goehr, The Imaginary Museum (op. 21 zgoraj), str. 113.

M. Talbot, 'The Work-Concept' (op. 21 zgoraj).
} 
poprej še nikoli ni zgodilo, kar pa je očitno neizvedljivo; to seveda nujno ne devalvira same trditve, ki pa le ostaja na ravni nekakšne besedne igre.

Toda: zakaj je sodobnikom toliko do postavljanja vedno višjih pregrad med segmenti preteklosti in zakaj moramo torej verjeti, da je srednji vek klasično-romantično-modernega koncepta dela (itd.) "šele pred kratkim" minil, da so bili doseženi kritični preboji in da je prišlo do "morskih sprememb" $\mathrm{v}$ zgodovini in kulturi?

Kaže, da gre za upravičeno postmoderno skrb glede tega, da stare meta-pripovedi o napredku, racionalizaciji, konceptu dela, središčnosti skladatelja (itd.) zaznavno obvladujejo naša življenja. Da bi se ta bojazen artikulirala, sta se oblikovali novi metapripovedi o "razvodju“ in "morski spremembi". Verjetno ni slučaj, da je v obeh primerih uporabljena samovšečna metafora vode: zgodovina naj bi se tako kot vodni tok spreminjala "naravno", neškodljivo in brez napora. Implicira se misel, da se je modernistična doba zadnjih dveh stoletij, ta vir naših bojazni, naravno zaključila. Pred to dobo, je bilo bolje, in sedaj, po njej-bo zopet bolje.

Mislim, da sem pokazal, da je meta-pripoved postmoderne usmeritve taka, kakršna je bila modernistična. Gre za progresivno pripoved, po kateri nam je sedaj, ko smo od modernizma prešli k postmodernizmu, bolje. Tako ni nastop postmodernizma $\mathrm{v}$ resnici spremenil te najbolj vplivne meta-pripovedi, ki implicira naravnanost, $s$ katero se ne morejo identificirati postmoderni odnosi do zgodovine, kakor so jih razglašali Foucault, Eco ali Lyotard. Če je, kot pravijo omenjeni pisci, dosežek postmodernizma v dvomu v meta-pripovedi, potem niso v položaju, v katerem bi lahko trdili, da smo spremenili svet. Raje bi se bilo vprašati, kaj se je v resnici spremenilo, in ugotoviti, ali se je spremenilo na boljše ali na slabše. In nemara, še vedno lahko kaj postorimo, da svet izboljšamo.

\title{
Postmodern Problems in European Musical Historiography
}

\begin{abstract}
Summary
This essay addresses the question what music historiography may learn from the postmodern discourse as it is developing around us. The general historiographic implications of the concept 'postmodernism', as an improvement of and progress over 'modernism', seem to contradict its own message of incredulity towards progressist meta-narratives. A comparison is made between a negative attitude to the medieval past found in Renaissance humanism ('divided retrospection'), and postmodern discourses which apply the same optics to the last 200-250 years in Western culture. Some postmodern narratives concerning music are considered: antimodernism, the Baroque and Early Music movement, the reception of early opera, and the debates about work-concept, autonomy and authorship. The paperpoints out a danger that Lyotard's definition of postmodernism as "incredulity towards meta-narratives" is being sacrificed to a new meta-narrative which applies a divided retrospection, separating a rejected modernist past from an 'only recently' achieved breakthrough or 'sea change' in cultural studies.
\end{abstract}

